Sultan Qaboos University Journal of Arts \& Social Sciences

جامعة السلطان قابوس الإداب مجلة الآداب والعلوم الاجتماعية

\title{
The Acquisition of Syntax: A Nativist Perspective vs. a Cognitivist Perspective
}

\author{
Rashid Al-Balushi \\ Assistant Professor \\ Department of English Language and Literature \\ College of Arts and Social Sciences \\ Sultan Qaboos University \\ rash5222@squ.edu.om
}




\title{
The Acquisition of Syntax: A Nativist Perspective vs. a Cognitivist Perspective
}

Rashid Al-Balushi

\begin{abstract}
:
\end{abstract}
This paper looks into how two main frameworks view the acquisition of syntax. These are the nativist approach which claims that language is acquired because human beings are equipped with a language acquisition device in the form of grammatical knowledge, and the cognitivist approach which views language like the other cognitive skills and so claims that we acquire language using general cognitive mechanisms that are not specific to language. The paper reviews a number of studies that report on the acquisition of various aspects of the syntax of natural language; the studies are from both frameworks. The paper then evaluates the claims of the reviewed studies in light of the respective findings, as well as in light of how the findings may be interpreted by the other framework. The paper also presents an analysis of the argumentation techniques that the respective authors use, as well as of how effective they are. It concludes with a proposal for a line of research which is based on research techniques and findings in second language acquisition.

Keywords: nativist framework; cognitivist framework; acquisition of syntax; poverty of stimulus; universal grammar.

\section{اكتساب (تعلم) النحو من منظور فطري و منظور إدراكي}

راشد البلوشي

\begin{tabular}{ll}
\hline \\
\hline
\end{tabular}
تنظر هذه الورقة في موضوع اكتساب أو تعلم النحو (أو القواعد النحوية) كما يتم بحثه في اثنين من الأطر النظرية الهامة. يعتمد أحد هذه

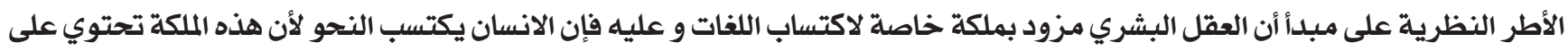

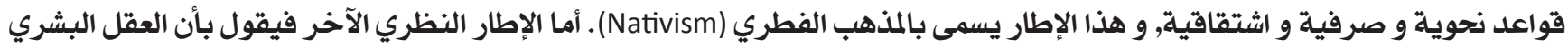

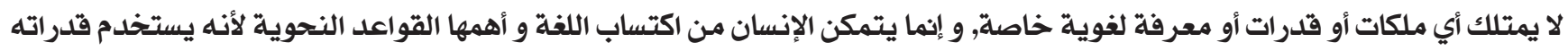
المعرفية و الإدراكية العامـة التي يستخدمها لتعلم أي مهارة معقدة أخرى, و هذا الإطار يسمى بالمذهب الإدراكي (Cognitivism). الورقية

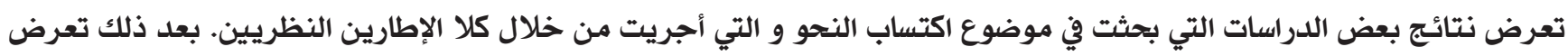

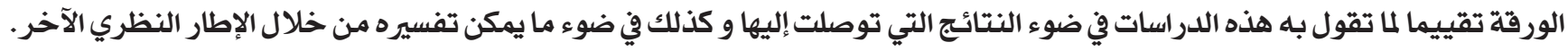
و تعرض الورقة أيضا تقييما لاستراتيجيات التحليل و الجدال التي اعتمدها الباحثون. تختم الورقة باقتراح مجال بحثي يعتمد مبادئ من علوم اكتساب اللغة الثانية و يوضِح أنه مجال خصب لتوضيح ما إذا كان العقل البشري يحتوي على ملكات لغوية خاصة أم لا. الكلمات المفتاحية: المذهب الفطري. المذهب الإدراكي. اكتساب النحو. ضعف المثير اللغوي. القواعد اللغوية العامـة. 


\section{Introduction}

This paper presents the issue of acquisition of syntax as viewed from a nativist perspective and a cognitivist perspective. The nativist view is based mainly on the poverty-of-the-stimulus argument, which states that the linguistic environment (input) is not rich enough to enable the first language learners to reach adult competence, and so is insufficient to explain their knowledge and understanding of their first language. Therefore, language or grammatical knowledge is innate, which is why the language learner can achieve ultimate attainment from impoverished input. Thus, language is considered as a modular domain. The cognitivist view, on the other hand, is based on the assumption that language is acquired by innate capacities that are not specific to language, rather ones that are available for all cognitive skills. Therefore, language is viewed like other cognitive skills; that is, it does not constitute a module in the brain.

The poverty-of-the-stimulus argument has been a source of stimulation for a huge body of research providing evidence both for and against it. This paper will present and evaluate some of the empirical research conducted in both frameworks. The aim is to make the picture clearer with regard to how both frameworks view the acquisition of syntax and how researchers believe the acquisition of syntax proceeds, which, in turn, formulates their conceptions of the argument and its reality.

Section 2 presents what both frameworks assume the acquisition of syntax (and language in general) to be. Section 3 discusses some of the empirical research conducted in the nativist paradigm to characterize the acquisition of syntax. Section 4 discusses some of the studies conducted in the cognitivist paradigm to illustrate the particulars of the syntax learning task. Section 5 evaluates the findings and claims of the discussed studies, and shows how they can be interpreted and accounted for by the other side. Section 6 points to a solution. Section 7 concludes the paper.

\section{Acquisition of Syntax}

The nativists claim that the capacity for language (acquisition) is built into the human mind. The human brain contains a dedicated special-purpose learning device that has evolved for language only, called the Language Faculty. Chomsky's (1965) description of natural language syntax revealed the complexity of the grammar that we acquire as we learn our first language. This led to speculations on the relationship between the complex nature of grammatical knowledge and the way it is acquired by the human species, which paved the way for the poverty-of-thestimulus argument.

Thus, the nativists believe that human beings learn a language because they possess a Language Faculty that tackles the complexity and novelty of grammar. For them, linguistic input, so-called Primary Linguistic Data (PLD), triggers the Language Faculty, and as we are exposed to language we, unconsciously and with the desire and need to communicate, formulate hypotheses about the structure of the language and test them, unconsciously, against additional data. The language learner embarks on and continues this enterprise until his/her grammar matches that of the adult native speaker of the target language. As it became clearer that many languages share many grammatical principles, categories, and operations, Chomsky (1971) proposed the existence of a Universal Grammar (UG) that encompasses all the possible linguistic structures that a human language can have. This UG is composed of grammatical principles that are accessible to all language learners as well as of parameters, which are the language-specific realizations of these principles.

The nativists' position is supported by several arguments (discussed and elaborated on in Pinker 1994). Pinker argues that language is special because it is acquired, produced, and perceived without instruction. Second, language speakers produce and perceive sentences that they have not encountered before. Third, the grammars of the languages of the world have certain characteristics that reflect a universal complex linguistic structure in the brain. Fourth, the initiation of creoles with standardized word orders and grammatical markers that were absent in the respective pidgins reflects the ability to parse, analyze, and operate linguistic systems. Fifth, deaf children's ability to acquire and initiate sign languages using the same grammatical machinery found in spoken languages indicates the existence of an inborn capacity for language. Sixth, the presence of a critical period for first language acquisition indicates that it is carried out by a special biological device. Seventh, the acquirers are able to combine words according to mental algorithms that go beyond the application of linear rules. Eighth, children acquire rules that are not crucial for communication, like agreement, very early. Ninth, some patients with mental retardation (Williams Syndrome individuals) have normal linguistic 
abilities. By contrast, many linguistically retarded patients can display organized and sound thinking. These arguments indicate that language and cognition are not related, and so we must be equipped with an innate linguistic component in our brains. Basically, the nativists argue that language is acquired because the brain is good for language.

The cognitivists, on the other hand, argue that language is learnt by a complex computational power which evolved to serve many goals of human cognitive activity. In other words, they acknowledge that language is acquired by an innate device, but that this device is neither a grammatical blueprint (UG) nor is it specific to language (Language Faculty), and thus argue that language and cognition are related.

The cognitivists argue that language acquisition obtains as a result of various cognitive, social, pragmatic, world knowledge and physiological constraints like memory capacity, communicative needs and analytical abilities. For example, they argue that learners of Chinese (a language without fixed word order or case markers) make use of all these resources as well as of probabilistic cues and the semantic content of words to resolve ambiguity and produce and comprehend their language. Moreover, the human memory capacity sets limits on the possible acquired grammars since a rule that reverses the words in a sentence to form a question is not available in any language. Instead of formal rules, the cognitivists argue that language is composed of linguistic symbols, which human beings have created for purposes of communication, and so they believe that we come to learn language because we need it for communication, not because it is in our brains. Tomasello (1995:150) argues that "[a]॥ groups of human beings have at their disposal some combination of four and only four linguistic devices for communicating experience: individual symbols (lexical items), markers on symbols (grammatical morphology), ordering patterns of symbols (word order), and prosodic variation of speech (e.g., stress, intonation)".

Since they argue that form follows function, the cognitivists state that all we need is a structured inventory of symbolic devices the use of which is conventional, and so we need no rules, parameters, nor linguistic constraints. Thus the child's task will be to discover how people use and string these symbols together. Tomasello (1992) argues that children make use of vocabulary-acquisition-like mechanisms and strategies when acquiring grammar. They use, he states, joint attention and pragmatic inference, which are used to understand adults' use of lexical symbols. He points out that linguistic category formation is a cognitive as well as a social process. It is social because in all cultures there is some similarity in the situations in which children have to use language, which allows them to extract the semantic relations of agent, patient, and action. It is also social since, as children are exposed to linguistic input, they form paradigmatic word classes like nouns and verbs. This enables them to produce nouns and verbs (and other word classes) in positions where they have not been heard before. Tomasello (1992) concludes that this view of language and its acquisition is not mysterious in the way generative linguistics and nativism stipulate. Thus, language is likely to be acquired by more general cognitive ingredients. Basically, the cognitivists argue that language is acquired because language is good for the brain.

\section{The Nativist Studies}

This section discusses five studies that argue for the poverty-of-the-stimulus argument. Since it is far from easy to argue that children produce something they have not experienced (as evidence that they possess $U G)$, the nativists choose to investigate UG and show that children's utterances are in line with the principles and constraints of generative linguistics. They argue that if all language learners, in all acquisition environments, can attain the same grammatical system (principles, operations, constraints) despite the considerable variability in linguistic experience and lack of special training or carefully sequenced input, then this is due to possessing UG. This indirectly argues for the poverty-of-the-stimulus argument, since it shows that children know (or cognize) more than what they experience or produce.

Poeppel and Wexler (1993) analyzed 282 declarative utterances from the transcripts of a monolingual 25-month-old German child. The results show that the child's language production contains the major functional sentential categories, namely IP (Inflectional Phrase) and CP (Complementizer Phrase). This is because the child's utterances reveal his knowledge of finiteness, verb placement, agreement, and head movement, as well as the use of permissible word order variations. However, the child's language deviates from that of German speaking adults in the use of infinitives in matrix clauses. They argue that the child's language represents those infinitives as nonfinite main verbs, allowing them to appear in matrix clauses, which is in line with the researchers' 
Full Competence Hypothesis.

Guasti (1993) presents an analysis of longitudinal data from the transcripts of three monolingual Italian children (ages, $1 ; 8-2 ; 7,1 ; 10-2 ; 6$, and 2;2-2;7). The analysis is based on a total of 534, 660, and 217 utterances, respectively, for the three children. The results show that the children distinguish between finite and non-finite verbs, and that they are aware of the Italian agreement system. This, together with the children's knowledge of the placement of clitic pronouns, is interpreted as evidence that their utterances include functional categories, especially the IP.

Crain and Nakayama (1987) used an experimental procedure to elicit Yes/No questions. Thirty 3-to 5-year-old children were instructed to ask a puppet some questions. The experimenter would tell them to 'ask Jabba if the man who is feeding a donkey is mean'. The researchers wanted to see if the children would form the Yes/No question by moving to the front the first 'is' or the second 'is'. Based on utterances like (1-2), one would hypothesize that children form Yes/ No questions by inverting the first/leftmost auxiliary. However, given possible utterances like (3-4), the previous hypothesis is incorrect, but are children sensitive to this distinction?

1. the man is mean.

2. is the man mean?

3. the man [who is feeding a donkey] is mean.

4. *is the man who feeding a donkey is mean?

5 . is the man [who is feeding a donkey] mean?

Indeed, the results show that the children never produced utterances like (4); that is, they would produce (5) as a question to Jabba (other possibilities are examined in experiment 2). The researchers take these results to indicate that the children are aware of the Head Movement Constraint (HMC) of Travis (1984). This is because they did not extract the auxiliary from the relative clause, which is adjoined to the subject NP; rather, they inverted the auxiliary which occupies the head of the IP and moved it to the one-step-higher empty head position, C, to form the Yes/No question. Crain and Nakayama take this as evidence that children have access to UG. Though the children never produced utterances like (4), the younger group $(3 ; 2-4 ; 7)$ produced ungrammatical questions $62 \%$ of the time while the older group $(4 ; 7-$ $5 ; 11)$ produced ungrammatical questions $20 \%$ of the time (some of which conform to structures in other languages). The children produced questions like (6) where 'is' is inserted at the beginning and neither of the two 'is's' is deleted.

6 . is [the man who is feeding a donkey] is mean?

The authors hypothesized that the subject-auxiliary inversion rule consists of two smaller rules, copying of the auxiliary in the main clause and deleting it later. Thus, they assumed that children, for some reason, perhaps memory capacity limitations, forgot to apply the second rule, and so ended up with two 'is's' in the main clause. Therefore, they conducted experiment 2 with experimental sentences like (7-8), where the two auxiliary verbs are different, as follows.

7. [the man who is mean] can run.

8. [the man who can run] is mean.

This procedure was implemented to find out the source of the copy of the auxiliary that gets preposed in the question form. Despite the fact that the children's performance revealed even more incorrect responses, none of the observed responses showed deletion of the auxiliary of the relative clause, which conforms to the HMC. This, in turn, indicates that the sentence processing routines of young children and their hypotheses do not violate UG principles.

Crain (1991) argues that innate constraints tell language learners that certain sentences cannot have certain interpretations regardless of linear order. Thus (9) has the co-referential reading where 'he' refers to the 'Ninja Turtle' as the pronoun follows the R-expression. However, as this order is reversed in (10), it cannot have the co-referential interpretation; thus 'he' cannot refer to the 'Ninja Turtle' in (10).

9. the Ninja Turtle danced while he ate pizza.

10. he danced while the Ninja Turtle ate pizza.

11. while he danced, the Ninja Turtle ate pizza.

Though (10), where the pronoun precedes the R-expression, cannot have the co-referential reading, (11), which maintains the same order, can have the co-referential reading where 'he' may co-refer with the 'Ninja Turtle', but does not have to. The researcher presents this set of data, and argues that the fact that children are aware of it is evidence for their knowledge of the constraints that UG sets on sentence interpretation. This, he states, is because this aspect of linguistic knowledge has no decisive evidence in the input; thus it is encoded in UG.

Crain (1991) also examined children's knowledge of trace by testing their sensitivity to the restriction on 'wanna' contraction. In an experimental procedure, 21 2;10-to5;5-year-old children responded to experimenters' requests by addressing wh-questions to a puppet. These questions were both object extraction questions, like (12-13), and subject 
extraction questions, like (14-15).

12. who do you want to help $t$ ?

13. who do you wanna help?

14. who do you want to help you?

15. *who do you wanna help you?

It is clear that, in adult English, contraction is permissible in (12-13) because the contraction does not occur across a trace. However, this contraction is not allowed in (14-15) because it is ungrammatical to contract across a wh-trace. The results showed that children contracted in object-extraction questions, but resisted that in subject-extraction questions. The children produced the impermissible 'wanna' contraction only $4 \%$ of the time. This finding is taken as evidence for the children's knowledge of UGencoded constraints.

Crain and Thornton (1991) present a set of data, like (16-17), that look problematic for the above observation that children respect wh-phrases and never contract across them. This is because in (1617) the trace is between 'think' and 'is'. This issue was treated by Bresnan (1978) who proposed that contraction occurs to the material to the left (as in 'want to' where 'to' contracts with 'want' yielding 'wanna') and to material to the right (as in 'is in' where 'is' contracts with 'in' yielding 's'in'). Thus, despite orthography, 'is' is contracting to the preposition 'in' rather than to 'think'. Thus (16) should look as in (18). 16. who do you think $t$ is in the box?

17. who do you think's in the box?

18. who do you think $t s^{\prime}$ in the box?

Crain and Thornton state that this is in fact true. Thus they hypothesized that contraction is not allowed when the trace intervenes between 'is' and the material to its right. To test this hypothesis, they designed an experiment that encouraged the children (ages $2 ; 11-4 ; 5)$ to ask questions like (19-22).

19. do you know what that is doing t up there?

20. do you know what that's doing t up there?

21. do you know what that is t up there?

22. *do you know what that's t up there?

The results showed that "there was not a single instance of contraction where it is ruled out in the adult grammar" (Crain 1991:604). The authors argue that sensitivity to this subtle distinction of direction of contraction is evidence for children's knowledge of UG, and thus constitutes a convincing case for the poverty-of-the-stimulus argument.

\section{The Cognitivist Studies}

This section discusses three studies that attempt to provide an explanation for the acquisition of syntax based on various aspects of human cognition. These aspects are supplied by the different mental computational capacities that the human brain utilizes and exploits for language acquisition as well as for learning other complex cognitive skills. The researchers stress that the acquisition of syntax can better be explained via a usage- and experience-based approach. They argue that the child language learners' production reflects either what they hear from their caregivers (motherese) or what they experience in an artificial (experimental) learning situation.

Tomasello and Brooks (1998) provide evidence that children's earliest utterances are exclusively determined by their linguistic experiences. Their aim was to find out whether children's earliest utterances show verb-specific understanding (lexically-based formulas) or verb-general understanding (abstract mental grammatical templates) of the transitive and intransitive constructions. According to the former position, if a child says 'I eat apple', this would indicate the presence of more concrete lexically-based templates like (EATER-EAT-EATEE) or (NP-EAT-NP). As for the latter position, if a child says 'I eat apple', it would mean that the child's competence consists of an abstract schema like (S-V-O) or even (NP-V-NP). The authors argue for a lexically-based nature of the utterances produced by children in the early phases of language acquisition. They also hypothesized that the younger children would not produce the novel verbs in constructions in which they have not been modeled, whereas the older ones may use verbs heard in transitive constructions to produce novel intransitive utterances (for syntactic simplicity), but not vice versa.

Sixteen 2-year-old and 16 2;5-year-old children participated in this study. Two novel verbs, 'meek' and 'tam', were taught and modeled to describe novel actions that can be performed with a novel apparatus (puppets as subjects/agents and objects/patients). Both verbs were modeled in transitive and intransitive constructions. Each child learned one of the novel verbs in a transitive construction and the other verb in an intransitive construction. Children were tested individually, and their linguistic performance was both written and audiotaped. In the first session, the children heard 128 utterances with the two verbs, in both constructions. In the second session, 24 additional models were added for each verb. In both sessions, discourse pressure was provided to cause the children to produce the novel verbs in constructions 
(transitive or intransitive) in which they have not been heard modeled. The linguistic modeling as well as the performance elicitation processes provided equal opportunities for both verbs in both constructions.

The results showed a great matching to the adult models. The 2-year-old children showed greater conservativeness (utterances matching the adult models in transitivity) than creativity (not matching the adult modeling). The average number of matches per child across constructions was 9.1, roughly equal to seven times the average number of mismatches across constructions, which was 1.3. The 2;5-yearolds talked significantly more than the younger group. The average number of matches per child across constructions was 28.8 , roughly equal to nine times the average number of mismatches across constructions, which was 3.2. However, the 2;5-yearold children used the intransitive verb transitively (contrary to expectation) when pressed to do so, and approximately one third of them used the transitively modeled verb in an intransitive utterance. While fourteen of the older children were creative, only seven of the younger ones were creative. These results indicate that, early in language acquisition, the utterances of 2-year old children are significantly determined by the adult models, and that the majority of these children do not have an abstract transitive nor intransitive schema that can assimilate new verbs. Akhtar (1999) was conducted to investigate whether English-speaking children are open to learning nonSVO structures with novel transitive verbs. If so, the researcher hypothesized, then the parameter-setting account of grammar acquisition is invalid. This is because the parameter-setting account assumes that children bring grammar to the language learning task, and thus predicts that acquisition of the basic word order may be accomplished very early, and that once the parameter is set, the child's grammar will not be affected by subsequent exposure to word orders. Therefore, argues Akhtar, the notion of datadriven learning is a better explanation of grammar acquisition. In other words, language is out there in the linguistic environment, with the input (PLD) being its sole source.

Thirty-six children served as subjects. They were divided into three equal age groups: 2-, 3-, and 4-years old. Three novel actions were constructed: 'tamming', 'gopping', and 'dacking'. These verbs, together with animate agents (subjects) and inanimate patients (objects), helped in constructing sentences in three word orders: SVO, SOV, and VSO. The children were familiarized with the experiment situation as well as with their task. Before the children's language production was elicited or recorded for analysis purposes, they all attended a teaching session where they were seen individually, and it was made sure that they knew the names of all the toys and puppets. In the experimental sessions the children were exposed to all three of the novel verbs and were required to perform and verbally describe the actions. This was done using the puppets and the toys. Only the nonimitative child utterances with both the agent and the patient of the action expressed were included in the analysis.

The results showed that the younger children (2- and 3 -year olds) were equally and more likely to accept and produce the non-SVO word orders with the novel verbs. In contrast, the 4-year-olds were more conservative, showing resistance to using or accepting the non-SVO orders with the novel verbs. In order to eliminate any conformity effects on the part of the children, a control condition was carried out. The assumption was that if children acquire word order on a verb-by-verb basis, then they would have already known the right word order with a familiar verb (e.g. 'push') and so will adhere to SVO. The children were then exposed to utterances utilizing a familiar verb in non-SVO word orders. The results showed that all the children corrected the non-SVO utterances to the English SVO order several times, and that only three of them matched the non-SVO order with the familiar verb.

These results are taken to support the data-driven account of syntax acquisition. This is because, argues Akhtar, had the children had the parameter set in their brains to the English value, they would not have tolerated or produced any non-SVO utterances. However, since they do not have grammar in their brains, Akhtar concludes, their source of grammar was the input which determined their language production. The data-driven learning approach stipulates that "children tend to be quite conservative and use verbs only or mainly with the argument structures with which they have heard them used" (Akhtar 1999:352). Therefore, the amount of exposure to the SVO order made the difference as the children were required to produce or accept the non-SVO orders.

Theakston et al. (2001) investigated the role of the limitations seen in the performance of children in their early acquisition of verb-argument structures. Their study aimed to provide an alternative explanation for 
the observation that intransitive frames are easier for children to produce early in development than transitive frames. The previous explanation states that intransitive frames precede transitive ones for syntactic simplicity, or due to children's limited memory capacity. Such positions predict that young children will produce a greater proportion of intransitive verb utterances than children who are more advanced in their language development, and that, over time, as processing restrictions decrease, children will show a proportional increase in their use of transitive verbs. The researchers' alternative explanation states that the best predictor of the frames used by the children with specific verbs would be the frames used by their mothers with those same verbs, regardless of syntactic complexity. Therefore, the authors hypothesized that the children's use of verb frames with individual verbs will reflect the use of verb frame in the input, and that the verbs that the children acquire early will be found with higher frequency in the input than the verbs that the children acquire later in the development.

Nine children from middle class families participated in this study. Their mothers were their primary caregivers. Their ages ranged from 1;10,7 to 2;0,25. Their Mean Length of Utterance (MLU) ranged from 1.06 to 1.79 in morphemes. They were audiotaped in their homes as they were interacting with their mothers for an hour on each of two separate occasions in every threeweek period for one year. The data were transcribed and the MLU was calculated. The data were divided into stages based on MLU. Experimentally improper utterances were excluded from the children's and their mothers' utterances. The verbs in the children's utterances were coded for transitive, intransitive, or mixed. For comparison purposes, the mothers' data were examined; the verb frequency in the input was correlated at the first and the last recordings, with a year interval.

The results revealed a general trend among the children to show an increased proportional use of transitive verbs at stage three (later in the development) accompanied by a decrease in the proportional use of intransitive verbs compared to stage one (early in the development). The children showed an increase in the proportional use of optional direct object arguments with their mixed verbs. Although these findings have been predicted by other approaches in addition to the one adopted in this study, the difference is with the best predictor of this pattern of results. To illustrate, there was a significant correlation between the average proportional use of the transitive frame with of acquisition. This suggests that the most important predictor of children's use and acquisition of verb frames is the input, regardless of transitivity.

\section{Evaluation of Findings and Claims}

This section evaluates the studies discussed in sections 3 and 4 in terms of whether their claims follow from their findings, and what this means for them and for the other side, as well as how their data may be interpreted by the other side.

Poeppel and Wexler (1993) presents a case for the involvement of UG in language acquisition since it shows that the universal elements (IP and CP) that are characteristic of all languages are available in child language. This supports the view that children engage in the language learning task already equipped with grammar. The study reveals that the language of a German speaking child is different from adult speech only in that the child uses infinitives in matrix clauses. The authors also use their findings to argue against accounts that assume children's grammars to be degenerate inflection-wise. They present two types of evidence, child language data that are largely in line with adult speakers' language, and analysis of the data that is in line with the predictions of the adopted linguistic theory. This lends support to the depth of the analysis as well as to its psychological reality. The analysis is both observationally and descriptively adequate since it accounts for the data and interprets them in terms of widely held linguistic assumptions. It is also explanatorily adequate as it addresses language acquisition. One possible limitation to the findings of the study is that the conclusions are based on data from one child. Also, the authors' justification of the child's use of infinitives in matrix clauses does not seem to be based on formal linguistic generalizations. They handle this by positing the Modal-Drop Hypothesis, according to which children tend to drop modals in sentences (main clauses), making them look like matrix infinitival clauses. Moreover, the authors do not consider cognitivist accounts, which could say that the child's language, regardless of what functional categories it includes, is a reflection of the input. Nonetheless, the fact that the child uses infinitives in matrix clauses, something that the child has not experienced, argues against experience-based approaches.

Guasti (1993) claims that her data indicate that young Italian children's speech includes functional categories, specifically the IP. Thus she argues that children are aware of the grammatical system that makes up their 
competence, and that their utterances obey the same grammatical principles and mechanisms that adult Italian speakers' utterances are derived from. The author also uses her data and analysis as further evidence that early grammars include functional categories, in line with Poeppel and Wexler (1993) and Weissenborn (1990). Being based on learnability type of evidence and formal type of evidence, Guasti's evidence looks deep, and makes the argument stronger, which, in turn, speaks for its psychological reality. Since it accounts for the child data in terms of an attested linguistic theory, the author's analysis is both observationally and descriptively adequate. It is also explanatorily adequate as it explains why children's utterances are the way they are without having to say that they simply reflect the input. The author, however, does not consider cognitivist interpretations of the data. A cognitivist would argue that the children's utterances are similar to those of the adult speakers because children's utterances are expected to reflect the input, without the need to use technical terminology like the IP.

Crain and Nakayama (1987) (as well as Crain 1991, and Crain and Thornton 1991) present another case for the availability and operativity of universal constraints on well-formedness, since the final-state grammar that children reach seems to result from two resources, UG and the input. These learnability findings, together with discoveries in the formal study of linguistics crosslinguistically, support the innateness of language. Despite the compatibility of these findings with the predictions of the nativist view of language acquisition, none of these studies shows that children's performance is qualitatively different from what they experience, or that they produced something they have not experienced, which is the basic tenet underlying the poverty-of-the-stimulus argument. Moreover, both experiments in Crain and Nakayama (1987) show that children produced ungrammatical questions in response to experimental protocols, which might count as evidence against the parameter-setting approach, since this could indicate that the parameters have not been set. The authors present a case for children being born with what allows them to form structure-dependent rules, which is the abstract grammatical knowledge. They show that children are able to form abstract computational structure-dependent rules that obey the HMC since the auxiliary of the relative clause is never deleted/moved. In general, the authors present a largely convincing case. Though their evidence is theoretically supported, it shows a lot of mismatches between adult speakers' English and the children's data. This discrepancy is justified by resorting to the performance-competence distinction and possible experimental biases as well as the assumption that children's memory capacity cannot handle longer chunks of speech. In addition, their analysis is largely observationally adequate and is descriptively and explanatorily adequate as the data are explained in terms of adult-language-governing constraints, and because the analysis makes correct predictions about the final-state grammar. A possible cognitivist explanation would state that the older group's performance is a sign of conservativeness, while that of the younger group indicates that they have not learnt the structure from the input yet. However, as children's utterances are supposed to be a reflection of adult speech, it is hard to argue that they are exposed to ungrammatical speech.

The results of Tomasello and Brooks (1998) show that some of the children's utterances were not similar to the adult modeling. Also, since the older children, contrary to what had been hypothesized, used the intransitively modeled verbs in transitive constructions, the authors' criterion of syntactic simplicity seems inadequate. Although the authors were trying to free the children's linguistic performance from any formal linguistic explanation, they could not avoid syntactic structure and regarded it as the only explanation. Nonetheless, they were able to show that children's early multi-word utterances are generally determined by the nature of their linguistic experiences. Therefore, the authors claim that their results indicate that children learn their first sentencelevel constructions on a verb-by-verb basis. Their evidence is based on the overall experience-based performance of children on the extension of transitive and intransitive frames to novel verbs. Their argument for their position is not convincing enough as it does not consider interpretations based on the theory of language underlying other analyses, nor is it based on the application of general cognitive principles to the syntax acquisition task. The authors' claim is based on a learnability/production type of evidence only (conformity to caregivers' speech), without further theorizing on the formal nature of what is acquired, how it is acquired, and why it is acquired, which puts limitations on how psychologically real their analysis is. Although the analysis is observationally adequate, it is not descriptively adequate since it does not address linguistically significant generalizations. 
Given the provisions of the cognitivist approach, this analysis is explanatorily adequate. However, given standard linguistics theory, or other explanations, it is not explanatorily adequate as it ignores the role of linguistic theory in explaining language acquisition phenomena. The authors do not consider nativist interpretations of the children's performance. According to the nativists, the children produced the transitive and intransitive sentences because they had set the respective templates with English verbs, and so they transferred this knowledge to novel verbs.

Although Akhtar's (1999) findings support the datadriven account of syntax acquisition by showing that grammar learning is a gradual process that depends on a sufficient amount of exposure to the target structure, there are a number of issues with this study. First, since the experimental setting (of the control condition) was able to make three children accept or produce the non-SVO orders with familiar English verbs, chances are that the experimental setting made them switch to the non-SVO orders with the novel verbs. Second, though the young children used and accepted the non-SVO orders, some of them corrected the non-SVO utterances to the English word order, and were more likely to use and accept the SVO order sentences than the non-SVO sentences. Third, the author removed from the analysis some child utterances that did not have both the subject and the object, like SV, VO, VS, and OV, where the first two can be taken to show that children have set the SVO parameter, and that their incomplete utterances are a result of their getting confused because of the experimental setting. The author seems to suggest that prior to being 4-years old, children do not have a generalizable knowledge of the word order of their mother tongue. A replication of this study with similar and older age groups is necessary to find out whether four-year-olds would behave similarly, and whether older children can be swayed, which would confirm or disprove the suggested age-point. Despite this, Akhtar claims that the acquisition of word order is both a gradual process and data-driven, based on the observation that English-speaking children are open to using novel verbs in non-SVO orders. She uses this (production data) type of evidence to argue that parameters do not exist as the SVO parametersetting does not seem to have taken place, since a Language Faculty assumes rapidity and accuracy of acquisition (Pinker 1994). The author's evidence is not conclusive because it does not do justice to a formal theory of language (generative linguistics, or other) that links syntax acquisition by children to that by adults (final-state grammar). This state-of-affairs renders this evidence as bearing little psychological reality. Since it does not do justice to the other possible analyses of those data, this analysis is not observationally adequate. Likewise, as it does not give fair account of how other analyses might handle the data (the widely held assumptions about the nature of language), it is not descriptively adequate. Also, since its interpretation of the data does not address, tackle, and justly dismiss all other possible analyses of syntax acquisition based on the provided data, it is not explanatorily adequate. Since this situation is arguably not different from a multilingual environment where children are exposed to more than one language (word order), the nativists would expect the children to learn novel verbs in non-SVO order sentences if they are exposed to them since the non-SVO orders are also part of UG (available in other languages).

Theakston et al. (2001), who show that grammatical complexity neither predicts the verbs acquired nor the frames in which they are used, seems to offer a reply to the syntactic simplicity criterion proposed by Tomasello and Brooks (1998) to account for the possibility that older children can produce transitively modeled verbs in intransitive constructions. The authors also sought to test the performance limitations account of children's early utterances of Valian (1991), where it is argued that, initially, children's utterances have more intransitive verbs than transitive ones, due to syntactic complexity, memory capacity, and the ability to encode and convey complex information. Since Valian's proposal is based on the competenceperformance distinction, it assumes abstract knowledge of syntax. While Theakston et al. state that their results are in line with Valian's predictions, they argue that the determiner of this performance pattern is not the performance limitations that Valian posits; rather, the utterances are determined by the children's mothers' speech (linguistic input). The verbs that the children acquired early in development were significantly more frequent in the input than the ones acquired later in development, which, argue the authors, makes the nativist account inadequate as it is unclear what role performance limitations play in early verb-argument production. The type of evidence the authors use is language production data, and they dismiss any role for memory capacity, syntactic complexity, and even children's ability to internalize and deliver language. Thus their claim does not seem to be supported by psycholinguistic generalizations, 
which undermines its psychological reality. This is because their data and interpretation do not rule out the existence of UG. From the cognitivist perspective, the analysis is observationally, descriptively and explanatorily adequate. However, given nativist criteria, the analysis is inadequate as its explanation of the syntax acquisition task does not appeal to syntactic constraints and principles. The nativists would interpret these data as not incompatible with UG-based accounts as it is expected that children's speech be largely a reflection of their linguistic experiences since, after all, it is these experiences that trigger the relevant parameters to be set.

Based on this discussion and critique, the authors of the nativist studies argue that if children's utterances are analyzed and governed by the same principles that govern adult speech of the respective languages (as well as other languages), then all children are born with a shared asset, UG. These studies, thus, are more thorough in addressing the poverty-of-the-stimulus argument since they show that what the children produce is in line with the predictions of the theory of language (generative linguistics) that they advocate.

By contrast, the authors of the cognitivist studies seem to argue that what is invisible, like UG and competence, is unavailable and thus inaccessible, and so its involvement in the acquisition of syntax is questionable. Therefore, the cognitivist studies seem more direct in addressing the issue of the povertyof-the-stimulus argument since they show that what the children produce is what they experience. Nonetheless, the findings of the cognitivist studies do not necessarily dismiss the existence and operation of UG. On another reading, they actually provide evidence for UG, and thus for the poverty-of-thestimulus argument. To illustrate, Akhtar's (1999) finding that English speaking children are open to learning non-SVO word orders supports UG as all these word orders are permissible given the principles of UG. Likewise, even where children's performance reflects the input, as Tomasello and Brooks (1998) and Theakston et al (2001) suggest, it is not necessarily the case that the performance is determined (solely) by the input; that is, it might still be determined by the competence which is provided and governed by UG.

Besides, it seems that the cognitivist researchers do not agree on a uniform definition for conservativeness. Tomasello and Brooks (1998) used conservativeness to explain why the younger children's utterances matched the adult modeling in the teaching and experimental sessions, whereas Akhtar (1999) used conservativeness to explain why the older children's utterances were consistent with their preexperimental experiences. Moreover, the cognitivists do not provide any explanation for the similarity between the linguistic principles that many languages have, and for the observation that children's utterances, regardless of what language they end up learning, seem to obey the principles of UG that only generative linguistics can account for. In addition, many of the findings in the cognitivist paradigm can be criticized because of some exceptions in children's performance that go against the authors' predictions (the same thing is arguably true of some of the nativist studies), which reflects that their utterances are not an exact reflection of the input, which, in turn, indicates that they are doing with the input something unexplainable by the cognitivists. Furthermore, the surveyed cognitivist studies have not empirically shown the claimed association between language and cognition. In other words, they did not show the applicability of any cognitive principle to grammar acquisition, which they might use to argue against UG governing the grammar of any language.

Despite this, it is hard to judge who wins the learnability contest, since neither are the cognitivists' findings necessarily against the poverty-of-thestimulus argument nor are the nativists' findings conclusively for it. Section 6 provides a perspective towards a solution based on research in Second Language Acquisition (SLA).

\section{A Perspective from Second Language Acquisition} Given this situation where the cognitivists do not accept the view that children's utterances obey UG and that they know more than they seem to, and where the nativists cannot show that children's utterances are qualitatively different from their linguistic experiences, another avenue must be explored. Conveniently, research in the field of Second Language Acquisition has been lending itself to this task. It has shown that even adult L2 learners can access UG. For example, research conducted to test the Fundamental Difference Hypothesis (FDH, Bley-Vroman 1988) shows that even adult language acquirers can achieve on Grammaticality Judgment Tests within the range of native speakers, as evidence that they too can have access to UG, as shown in Dekeyser (2000). The fundamental difference is that while children can avail themselves of their neural plasticity, adults take advantage of their advanced verbal and analytical abilities. Moreover, the 
Markedness Differential Hypothesis (MDH, Eckman 1977), which states that "the areas of difficulty that a language learner will have can be predicted on the basis of a systematic comparison of the grammars of the native language, the target language, and the markedness relations stated in universal grammar" (Eckman 1977:321), draws on the notion of UG. It explains the difficulty in "second language acquisition by comparing the relative markedness of structures in the L1 and the L2" (O'Grady et al. 2005:407). However, since various studies have shown that "learners are more likely to acquire a frequent but marked structure before an infrequent but unmarked structure than vice versa" (Ellis 1997:70), giving a more critical role to the linguistic input that learners are exposed to, thus setting limitations to the MDH, Eckman (1996) proposed the Structural Conformity Hypothesis $(\mathrm{SCH})$. The $\mathrm{SCH}$ states that "all universals that are true for primary languages are also true for ILs [interlanguages]" (Eckman 1996:204); that is, "ILs are languages (linguistic systems) in their own right" (Eckman 1996:205). This way, language production of L2 learners is always systematic or UG-governed. The SCH was tested in syntax (Eckman et. al. 1989) and phonology (Eckman 1991). In both studies the participants' ILs contained structures and elements that belong neither to their L1s nor to their L2s, hence belonging to UG, thus providing evidence for the plausibility of the $\mathrm{SCH}$, and therefore to the involvement of UG in L2 acquisition.

In addition to these hypotheses, there are others the investigation of which examines the role of both $L 1$ and UG in the task of $L 2$ acquisition. For example, the Full Access Hypothesis (FAH) states that UG is available to the L2 learners in the same way it is available to their L1 counterparts (Epstein, Flynn and Martohardjono 1996, Flynn 1987); that is, the adult L2 learners will directly access UG as they learn their L2. The proponents claim that "the parameters already set to the learners' L1 values do not influence their L2 initial analyses of the input they encounter" (Slabakova 2001:14), and so they speak of L2 parameter setting not L2 parameter resetting. FAH has been supported by the findings of Flynn (1983), Birdsong (1992), and White and Genesee (1996), among others. Another variant, the Full Transfer Full Access Hypothesis (FTFAH), states that besides UG, L2 learners also have access to their L1 grammar. In other words, there is full transfer from L1, as well as full access to UG (Schwartz and Sprouse 1996, White 1985), so there are both parameter setting and resetting. FTFAH is supported by the findings of Özçelik (2009), among others. The Partial Access Hypothesis (PAH), on the other hand, states that UG is accessible to the L2 learners only via $\mathrm{L} 1$; that is, the $\mathrm{L} 2$ learners may access the principles of UG, but that they can only access the parametric values instantiated in their L1s. In other words, they will learn their L2 only through UG structures that are L1-instantiated (Schachter 1989, 1990). It is clear that research in SLA provides support for the involvement of UG in language acquisition, hence for nativism.

An important line of research that SLA can provide a valuable source of data and insight in is one where researchers examine the acquisition of L2 structures/elements that are neither available in the learners' respective L1s nor in the L2 input/ data they are exposed to. This is because it will be easier for the researchers to examine whether the learners' performance (which informs about their competence) is different from their experiences or not. This is especially fruitful in situations where the second language (L2) is learnt in a classroom setting and is not the means of communication in the society, since it would be clearer to the researcher which of the L2 structures and elements the learners have experienced and which they have not been exposed to. This situation is dubbed Foreign Language Learning (FLL). In this case, the researcher can examine the $L 2$ learners' sensitivity (which would indicate, at least, tacit knowledge) to L2 structures and elements that have not been introduced in the curriculum and importantly ones that are not shared between the two languages.

This insight was inspired by Dekydtspotter et al. (1998) who used some of the properties of the French construction known as Quantification at a Distance (QUAD) to provide evidence for full access to UG in L2 acquisition (L2A). The QUAD structure refers to placing a quantity expression in a preverbal position binding a null determiner position, as in (23), whereas a non-QUAD structure refers to placing the quantity expression as a determiner, as in (24); QP is Quantifier Phrase.

23. [IP II a [VP [QP beaucoup]i trouvéi [NP [QP ei ] de pieces d'or]]]].

he has many found of coins of gold

'He found many gold coins.'

24. [IP I| a [VP trouvé [NP [QP beaucoup] de pieces d'or ]]]]

he has found many of coins of gold

'He found many gold coins.'

The non-QUAD structures can co-occur with single as 
well as multiple events, whereas the QUAD structure can co-occur with modifiers compatible with multiple events, but not single event contexts. Thus while the non-QUAD structures can have two interpretations, as (25) shows, the QUAD structure can convey one interpretation only, that is, the multiple events one, as (26) shows. This implies that the non-QUAD structures can carry out roughly the same semantic function as the QUAD structure, which suggests that it may not be acquired even when introduced explicitly. Nonetheless, the authors show that the QUAD structure is acquired by English-speaking L2 learners of French despite a severe poverty of the stimulus as well as absence of L1 help, which implies a role for innate grammatical knowledge.

25. II est passé beaucoup de bateaux a l'ecluse. it is passed a lot of ships at the lock

'Many ships passed the lock.'

(non-QUAD: two interpretations: Object-related and Event-related; that is, many ships and many crossings) 26. II est beaucoup passé de bateaux a l'ecluse. it is a lot passed of ships at the lock

'Many ships passed the lock.'

(QUAD: one interpretation only: Event-related; that is, many crossings)

Secondly, even in cases of non-iterable events like manger 'eat' where there is a one-to-one correspondence between eating and the eaten object, a non-QUAD structure may replace a QUAD structure. Although the QUAD structure seems to form a subset of the non-QUAD structures, there is a subtle interpretive distinction between the QUAD structure and the corresponding non-QUAD structures that convey approximately the same meaning. Sentences (27), QUAD, and (28), non-QUAD, show the semantic difference arrived at only by syntactic means.

27. Jean a beaucoup mangé de pains au chocolat. Jean has a lot eaten of croissants chocolat 'Jean ate many chocolate croissants'

28. Jean a mangé beaucoup de pains auchocolat Jean has eaten a lot of croissants chocolate

'Jean ate many chocolate croissants'

Since this means that there is no situation in which a QUAD sentence can be true and a non-QUAD sentence can be false, $L 2$ input is said to be insufficient with regard to the exposure to the QUAD structure. Therefore, the authors argue that unless there is full and direct access to UG, it is not possible to acquire the QUAD structure that is discussed neither in the pedagogical grammars of French nor in the classroom presentations. Thus, in order to probe the interpretive properties of the QUAD structure that is paired only with multiple-event interpretations (events and modifiers), they conducted two experiments. 160 English-speaking intermediate learners of French as well as 11 native speakers of French participated in the two experiments. In experiment 1 , they compared QUAD and non-QUAD sentences in terms of event sensitivity using an acceptability judgment test. The aim was to see whether the participants can identify the correct use of the QUAD structure; that is, to see if they can reject the QUAD structure in single event contexts. Thus, 12 sets of four French sentences were presented to the participants; two sentences in each set were a QUAD structure and the other two were a non-QUAD structure. Event type (multiple/ single) was indicated with adverbial material. In experiment 2, they compared QUAD sentences and frequency adverb sentences in multiple and single event contexts, as in (29) and (30), respectively, through a truth value judgment task. The goal was to find out whether the participants treat beaucoup in QUAD sentences differently from the corresponding frequency adverb.

29.ce soir, la reine Elizabeth II a beaucoup salué d'enfants

this evening the queen Elizabeth II a lot greeted the infants

'This evening, Queen Elizabeth greeted children a lot.' 30. beaucoup de fois ce soir, la reine Elizabeth II a salué des enfants

many times this evening the queen Elizabeth II greeted the children

'Many times this evening, Queen Elizabeth greeted children.'

The judgment task involved 13 sets of French sentences; each set contained 2 QUAD sentences and 2 sentences with an adverbial phrase. In general, the results of the two experiments indicate that the participants showed sensitivity to the use of the QUAD structure in multiple-event contexts; that is, they exhibited sensitivity to the syntactic and semantic properties of the QUAD structure. Therefore, the authors take these findings to indicate further support for the UG-based explanation of L2A. They argue that given the observed poverty of stimulus, lack of L1 help, and the fact that the semantic functions of the QUAD structure can be carried out by the corresponding non-QUAD structures to an acceptable degree of similarity, UG must have a major role in QUAD L2A, and thus, in language acquisition in general.

Thus research should pursue projects with similar 
structures in the respective L2s where neither the L2 input nor the L1 grammar can offer help. One such project can test access to UG by L2 learners by finding out whether child or adult learners would accept or produce, for example, the illicit contractions tested in Crain's studies. The L1s of those L2 learners should not have similar contraction phenomena.

Another project is to find out whether Arabicspeaking L2 learners of English can get the Surface Structure (SS, or c-command) reading of sentences like (31), where 'one book is given to every student/ all students' (universal quantification interpretation). It is noteworthy that Arabic speakers usually get the Logical Form (LF, or quantifier raising) reading of (31), where 'each student gets a book', since the SS reading is blocked or reserved by sentences like (32); 'every' in (31) is interpreted in Arabic as 'each'. If ArabicEnglish bilinguals can get the SS reading, then there is evidence that they have access to a UG possibility that is available in English.

31. I gave a book to every student.

32. I gave a book to all the students.

One more project is to test the sensitivity of the Arabic-speaking L2 learners of English for the negative inversion construction in (33-34), since Arabic does not have it, and it is introduced very late in the teaching process. One good point about negative inversion is that it is not motivated, neither semantically nor syntactically. It is not motivated semantically because the semantic/pragmatic function carried out by (33) is achieved by its ungrammatical counterpart, (34), which is not very unacceptable for beginner or even intermediate language users whose main goal, as well as that of their instructors, is communication and fluency, not grammatical accuracy. It is not motivated syntactically because subject-verb inversion is a property of questions not sentences, with this distinction introduced early on in the English as a Second Language (ESL) courses.

33. not only is he a kind person, but he is smart.

34. *not only he is a kind person, but he is smart.

One important issue to note here is what level of performance or sensitivity for the L2 structure(s) is a sufficient indicator for access to UG. Besides, it should be stressed that if UG is accessible to $L 2$ learners then this necessarily implies that it is accessible to L1 learners; however, showing its accessibility to L1 learners does not necessarily prove that $\mathrm{L} 2$ learners can also access it. This section is not meant to be a solution to the problem of learnability or the debate over language modularity; it is an attempt to explore a new, seemingly productive and insightful avenue.

\section{Concluding Remarks}

This paper has addressed the question of how syntax is acquired by first language learners and examined it in light of the research findings of two approaches, nativism and cognitivism. While nativism assumes a major role for the innate Language Faculty, cognitivism recognizes the linguistic input as the only source of language. The surveyed studies have shown how well the question is tackled and how insightful the provided answers are. Nonetheless, there remain many other questions related to whether UG is involved in language acquisition (and to what extent), and if so, how the cognitivists are going to account for their data. Other relevant questions involve how important the input (linguistic data) is to the language acquisition task, and if UG can compensate for the impoverished input, as commonly claimed by the nativists.

\section{References}

Akhtar, N. (1999). Acquiring basic word order: Evidence from data-driven learning of syntactic structure. Child Language, 26, 339-356.

Birdsong, D. (1992). Ultimate attainment in second language acquisition. Language, 68, 706-755.

Bley-Vroman, R. (1988). The fundamental character of foreign language learning. In W. Rutherford and M. S. Smith (Eds.), Grammar and second language teaching (pp. 19-30). New York: Newbury House.

Bresnan, J. (1978). Contraction and the transformational cycle in English. (Unpublished manuscript). Indiana University. Bloomington.

Chomsky, N. (1965). Aspects of the theory of syntax. Cambridge, M.A.: MIT Press.

Chomsky, N. (1971). Problems of knowledge and freedom. New York: Pantheon Books.

Crain, S. (1991). Language acquisition in the absence of experience. Behavioral and Brain Sciences, 14, 597650.

Crain, S. and M. Nakayama. (1987). Structure dependence in grammar formation. Language, 63, 522-543. 
Crain, S. and R. Thornton. (1991). Recharting the course of language acquisition: Studies in elicited production. In N. Krasnegor, D. Rumbaugh, R. Schiefelbusch and M. Studdert-Kennedy (Eds.), Biobehavioral foundations of language development (pp. 321-337). New Jersey: Lawrence Erlbaum Associates.

DeKeyser, R. (2000). The robustness of critical period effects in second language acquisition. Studies in Second Language Acquisition, 22, 499-533.

Dekydtspotter, L., S. Rex, and T. Rachel. (1998). Evidence for full UG access in L2 acquisition from the interpretive interface: Quantification at a distance in English-French interlanguage. In proceedings of the 22nd annual Boston University conference on language development 22 (pp. 141-152). Somerville, MA: Cascadilla Press.

Eckman, F. (1977). Markedness and the contrastive analysis hypothesis. Language Learning, 27, 315-330. Eckman, F. (1991). The structural conformity hypothesis and the acquisition clusters in the interlanguage of ESL learners. Studies in Second Language Acquisition, 7, 289-307.

Eckman, F. (1996). A functional-typological approach to second language acquisition theory. In W. Ritchie and T. Bhatia (Eds.), Handbook of second language acquisition (pp. 195-211). California: Academic Press. Eckman, F., E. Moravcsik, and J. Wirth. (1989). Implicational universals and interrogative structures in the interlanguage of the ESL learners. Language Learning, 39, 173-205.

Ellis, R. (1997). Second language acquisition. Oxford: Oxford University Press.

Epstein, S., S. Flynn, and G. Martohardjono. (1996). Second language acquisition: Theoretical and experimental issues in contemporary research. Brain and Behavioral Sciences, 19, 677-758.

Flynn, S. (1983). A Study of the effects of principal branching direction in second language acquisition: The generalization of a parameter of universal grammar from first to second language acquisition. (Unpublished PhD dissertation). Cornell University. Ithaca.

Flynn, S. (1987). A parameter-setting model of L2 acquisition. Dordrecht: Reidel.

Guasti, M. (1993). Verb syntax in Italian child grammar: Finite and nonfinite verbs. Language Acquisition, 3, 1-40.

O'Grady, W., J. Archibald, M. Aronoff, and J. ReesMiller. (2005). Contemporary linguistics. Boston: Bedford/St. Martin's Press.

Özçelik, Ö. (2009). L2 acquisition of scope: Testing the full transfer full access hypothesis. In M. Bowles, T. Lonin, S. Montrul and A. Tremblay (Eds.), proceedings of the 10th generative approaches to second language acquisition conference (pp. 168-179). Somerville, MA: Cascadilla Press.

Pinker, S. (1994). The language instinct. New York: Harper Perennial.

Poeppel, D., and K. Wexler. (1993). The full competence hypothesis of clause structure in early German. Language, 69, 1-33.

Schachter, J. (1989). Testing a proposed universal. In S. Gass and J. Schachter (Eds.), Linguistic perspectives on second language acquisition (pp. 73-88). Cambridge: Cambridge University Press.

Schachter, J. (1990). On the issue of completeness in second language acquisition. Second Language Research, 6, 93-124.

Schwartz, B., and R. Sprouse. (1996). L2 cognitive states and the full transfer/full access model. Second Language Research, 12, 40-72.

Slabakova, R. (2001). Telicity in the second language. Amsterdam: John Benjamins Publishing Company.

Theakston, A., L. Elena, J. Pine and C. Rowland. (2001). The role of performance limitations in the acquisition of verb-argument structure: An alternative account. Journal of Child Language, 28, 127-152.

Tomasello, M. (1992). The social bases of language acquisition. Social Development, 1, 67-87.

Tomasello, M. (1995). Language is not an instinct, a review of S. Pinker's "The language instinct". Cognitive Development, 10, 131-156. 
Tomasello, M. and P. Brooks. (1998). Young children's earliest transitive and intransitive constructions. Cognitive Linguistics, 9, 379-395.

Travis, L. (1984). Parameters and effects of word order variation. (Unpublished PhD dissertation). Massachusetts Institute of Technology. Massachusetts.

Valian, V. (1991). Syntactic subjects in the early speech of American and Italian children. Cognition, 40, 21-81.

Weissenborn, J. (1990). Functional categories and verb movement: The acquisition of German syntax reconsidered. In M. Rothweiler (Ed.). Sprachwerb und Grammatik, Linguistische Untersuchungen zum Erwerb von Syntax and Morphologie 3 (pp. 190-224). Sonderhefte: Linguistische Berichte.

White, L. (1985). The pro-drop parameter in adult second language acquisition. Language Learning, 35, 47-62.

White, L. and F. Genesee. (1996). How native is near-native? The issue of ultimate attainment in adult second language acquisition. Second Language Research, 12, 233-265. 